\title{
GATS - O ACORDO SOBRE SERVIÇOS DA OMC
}

Paula Santos de Abreu*

paula.abreu@aspectworld.com

\section{RESUMO}

Segundo a Organização Mundial do Comércio (OMC), os serviços representam atualmente $60 \%$ da produção global e $20 \%$ do comércio mundial. Como o desenvolvimento do comércio de mercadorias depende intimamente dos serviços, os países desenvolvidos vislumbraram novas oportunidades de expansão de seus mercados, principalmente os Estados Unidos que vinham perdendo mercado no comércio de manufaturas devido à baixa competitividade de seus produtos. Apesar da resistência de alguns países incluindo o Brasil ao acordo, logo perceberam que poderiam se beneficiar da abertura do comércio de serviços além de usa-lo como moeda de troca para abertura de outros mercados de seu interesse como o de produtos agrícolas, atualmente super protegido por subsídios na União Européia e EUA. Embora o discurso inicial fosse que o acordo seria abrangente, a abordagem ficou inicialmente restrita às áreas de serviços financeiros, telecomunicações e transportes principalmente. Inspirado no GATT, o GATS é então o primeiro acordo multilateral sobre serviços e funciona como um molde para que os países se comprometam na medida de seus interesses, regulando os tipos de medidas referentes à não-discriminação, transparência e regulamentação doméstica. $\mathrm{O}$ artigo analisa o acordo e as áreas mais atingidas.

Palavras-chaves: OMC, liberalização, serviços.

\section{GATS - General Agreement on Trade in Services}

\begin{abstract}
According to the World Trade Organization (WTO), services represent $60 \%$ of global production and $20 \%$ of world commerce. As the development of merchandise trade depends intimately on service, the developed countries could see new opportunities of expanding their markets, specially the United States that had been losing share in the commerce of goods due to the low competitiveness of their products. Despite the resistance of some countries to the agreement, including Brazil, they soon realized that they could also benefit from the liberalization of trade in services besides using their markets to negotiate liberalization of areas of their interest such as agricultural products, nowadays super protected by subsidies in the European Union and the US. Although the initial speech was that the agreement should be comprehensive, it ended up restricted to the financial services, telecommunications and transport mainly. Inspired from the GATT, GATS is the first multilateral trade agreement to cover trade in services and works as a framework, specifying the obligations of the members concerning non-discrimination, transparency and domestic regulation. This article aims to analyse the agreement and the most affected areas.
\end{abstract}

\footnotetext{
* Advogada. Pós-graduada em marketing pelo COPPEAD - UFRJ. Mestranda do Programa de Mestrado em Direito, área de Relações Internacionais do Centro Universitário de Brasília - UniCEUB. 
Keywords: WTO, services, liberalization.

\section{INTRODUÇÃO}

A prestação de serviços representa atualmente, uma contribuição vital para todas a atividades econômicas. A globalização do comércio de mercadorias levou à expansão paralela do comércio de serviços, já que depende deste para viabilizar sua própria existência. Serviços financeiros, de transporte, telecomunicações e muitos outros, estão intimamente ligados ao comércio de mercadorias $^{1}$ e em algumas economias, o comércio de serviços já superou o comércio de bens.

De acordo com a Organização Mundial do Comércio $(\mathrm{OMC})^{2}$, hoje o comércio de serviços representa $60 \%$ da produção global, 30\% da geração de empregos e $20 \%$ do comércio global. As exportações de serviços, segundo números do $\mathrm{GATT}^{3}$ em 1991, chegam a 890 milhões de dólares, concentrando-se em sua maioria nos países desenvolvidos, já que 70\% destas exportações são feitas pela América do Norte e Europa Ocidental (contra 62\% para as mercadorias) ${ }^{4}$.

Neste sentido, os países desenvolvidos viram alternativas para ampliar suas oportunidades comerciais, oferecendo serviços onde, tecnologicamente, são mais competitivos, tais como: telecomunicações, serviços financeiros, engenharia, dentre outros. Por outro lado, os países em desenvolvimento têm investido em outras áreas onde suas indústrias podem oferecer maior competitividade, como turismo e construção.

No entanto, a forma de prestação dos serviços poderia inviabilizar esta expansão, daí a grande necessidade de liberalização e regulamentação internacional, até para que também o comércio de mercadorias possa crescer.

O objetivo deste trabalho é justamente analisar os motivos e conseqüências da liberalização dos serviços através do $\mathrm{GATS}^{5}$, o primeiro acordo multilateral envolvendo serviços no âmbito da OMC, além de seu desenvolvimento.

$\mathrm{Na}$ primeira parte, faremos uma descrição histórica do acordo, partindo, então, para a

\footnotetext{
${ }^{1}$ CONDON, Bradly J. NAFTA, WTO and Global business strategy. Londres: Quorum Books, 2002, p.63.

${ }^{2}$ Informação disponível em: www.wto.org. Acesso em 27/04/2004.

${ }^{3}$ General Agreement on Ttariffs and Trade

${ }^{4}$ RAINELLI, Michel. A Organização Mundial de Comércio, Lisboa: Terramar, 1998, p. 117.

${ }^{5}$ General Agreement on Trade in Services

Revista do Programa de Mestrado em Direito do UniCEUB, Brasília, v. 2, n. 2, p.502-526, jul./dez. 2005
} 
conceituação de serviços e sua classificação que serão abordadas na segunda parte, dada a importância deste item para o entendimento da complexidade do assunto. A terceira parte é dedicada à análise das barreiras criadas pelos governos a fim de protegerem suas indústrias. $\mathrm{O}$ acordo em si será analisado na quarta parte. Por fim, discutiremos os setores mais atingidos e o futuro das negociações.

\section{HISTÓRICO}

Até a década de 90, não se falava em acordo sobre serviços. Todas as disposições existentes eram de natureza setorial e visavam apenas a elaboração de normas técnicas ou regras que viessem a facilitar os negócios internacionais ${ }^{6}$. Apenas alguns setores de serviços como finanças e transporte marítimo eram abertos como complemento ao comércio de mercadorias. Outros setores como hotelaria, restaurantes e serviços pessoais sempre foram considerados atividades domésticas que não precisavam de regulamentação. Outros segmentos da economia de serviços, desde telecomunicações a redes ferroviárias, eram para alguns governos, de seu domínio e controle exclusivo, dadas sua importância e relevância econômica e social, portanto não carecendo de políticas internacionais de controle $\mathrm{e}^{7}$.

Por este motivo, os governos protegiam suas indústrias através de regulamentos nacionais ${ }^{8}$ sobre o investimento e regras sobre a participação de serviços estrangeiros na economia doméstica. O comércio internacional era até então, visto como comércio de produtos, tangíveis, visíveis e transportáveis entre fronteiras ${ }^{9}$.

Com a difusão da internet e a redução das distâncias devido à tecnologia, a prestação de serviços foi extremamente facilitada e percebeu-se a magnitude do volume deste comércio. A necessidade de eliminar as barreiras para o comércio de serviços se tornou cada vez maior e o conceito de comércio internacional foi ampliado pela inclusão de discussões sobre o tema.

A primeira mudança na visão de comércio internacional se deu quando o Trade Act de 1974 nos Estados Unidos passou a incluir o comércio de serviços em toda interpretação que se referisse à

\footnotetext{
${ }^{6}$ MARCONINI, Marco. OMC, acordos regionais e o comércio de serviços:normativa internacional e interesse brasileiro.São Paulo: Aduaneiras, 2003, p.57.

${ }^{7}$ Disponível em: http://www.wto.org/english/tratop_e/serv_e/cbt_course_e/clslpl_e.htm. Acesso em 27 Maio 04.

${ }^{8}$ Estes regulamentos são considerados barreiras para o comércio internacional de serviços.

9 MARCONINI, Marco. OMC, acordos regionais e o comércio de serviços:normativa internacional e interesse brasileiro. São Paulo: Aduaneiras, 2003, p.57. 
“comércio exterior". ${ }^{10}$ Isso porque alguns setores manufatureiros nos EUA perdiam mercados, tanto internos quanto externos, devido à baixa competitividade de suas mercadorias, enquanto seu setor de serviços se mantinha forte e competitivo, especialmente na área de finanças e telecomunicações. $^{11}$

Sendo assim, a necessidade de um acordo sobre serviços passou a ser uma emergência e os Estados Unidos começaram a pressionar para que a Rodada do Uruguai abordasse o assunto. ${ }^{12}$

No início das negociações, os países em desenvolvimento, especialmente Brasil e Índia ${ }^{13}$, se opuseram ao acordo, pois, acreditavam que perderiam competitividade para as companhias americanas em alguns setores, alegando vários motivos: que a inclusão do tema desviaria a atenção para resolução de outros problemas do comércio de bens; que os países em desenvolvimento seriam obrigados a comprar tecnologia não necessárias às suas realidades ${ }^{14}$; que faltavam informações sobre as barreiras para o comércio de serviços e que deveriam dar suporte às indústrias locais antes da liberalização ${ }^{15}$.

No entanto, terminaram por perceber que poderiam se sobrepor onde a prestação de serviços estivesse relacionada à mão de obra mais barata, como na produção de softwares pela Índia, serviços financeiros e administrativos pela África do Sul aos vizinhos africanos ${ }^{16}$, dentre outros. Além disso, poderiam também se beneficiar da cadeia de produção de serviços, operando a parte da mão de obra desta cadeia. Egito, Chile e Filipinas aumentaram substancialmente o saldo de suas exportações devido ao aumento do comércio internacional de serviços ${ }^{17}$. No Brasil, os serviços em 1992 representavam mais de 57\% do PIB brasileiro, apesar de representar apenas cerca de 10\% das exportações ${ }^{18}$. Os países membros perceberam que o ganho do acesso aos mercados internacionais poderia ser substancialmente maior que o custo na mudança de regulamentos domésticos.

\footnotetext{
${ }^{10}$ Idem, p.57.

${ }^{11}$ HOWSE, Robert \& TREBILCOCK, Michael Jr. The regulation of Internacional trade. London: Routledge, p. 278.

12 Ainda assim, o NAFTA foi o primeiro instrumento a entrar em vigor com disposições sobre o comércio de serviços, apesar das negociações da Rodada do Uruguai terem começado antes.

${ }^{13}$ Outros países como Austrália, também comungavam desta opinião.

${ }^{14}$ GOYOS JUNIOR, Durval de Noronha. A OMC e os Tratados da Rodada do Uruguai. São Paulo: Observador Legal, 1994, p.52.

${ }^{15}$ HOECKMAN, Bernard M.; KOSTECKI, Michael M., The political economy of the world trading system. The WTO and beyond. Nova York: Oxford University Press, 2001, p.249.

${ }^{16}$ HODGE, James. Liberalization of trade in services in developing countries. In: HOECKMAN, B.; MATOO, A.; ENGLISH, Philip (ed.) Development, trade and the WTO. Washington: BIRD, 2002. p.224.

${ }^{17}$ HOWSE, Robert \& TREBILCOCK, Michael Jr. The regulation of Internacional trade. London: Routledge, 2001, p.279.

${ }^{18}$ Mensagem n. 498, de 29 de junho de 1994, do Presidente Itamar Franco ao Congresso Nacional submetendo os textos dos tratados da Rodada do Uruguai.

Revista do Programa de Mestrado em Direito do UniCEUB, Brasília, v. 2, n. 2, p.502-526, jul./dez. 2005 
Embora o discurso dos EUA fosse de que o acordo deveria ser abrangente a todos os setores de serviços, sendo apoiado por alguns países da OCED ${ }^{19}$, como os da UE, até mesmo Cingapura, a definição de serviços acabou por focar as negociações nos setores mais interessantes aos EUA e países desenvolvidos (transações cross border) ${ }^{20}$, excluindo a liberalização dos movimentos que relacionavam trabalho onde os países em desenvolvimento poderiam ter alguma vantagem competitiva. Além disso, os EUA não queriam apenas estender o princípio do Tratamento Nacional para o campo dos serviços, mas pressionaram para que mudanças nas legislações domésticas fossem efetuadas para permitir acesso aos mercados às empresas estrangeiras ${ }^{21}$.

Após vários impasses, a negociação chegou ao estabelecimento de um molde para determinados setores se baseando em compromissos aos quais os países se comprometeriam na medida de seus interesses, além de que o princípio do tratamento nacional seria especificamente setorial. Os EUA insistiam em excluir o setor de serviços marítimos do acordo e aprovar a abertura de acordos bilaterais onde não se aplicaria o princípio da nação mais favorecida (NMF). Isto porque alguns fornecedores americanos estavam visivelmente preocupados em terem de competir dentro de seu próprio mercado e alegavam que outros países não abririam seus mercados suficientemente para compensar a abertura de seu próprio. Para que a Rodada pudesse finalmente ser fechada no prazo estipulado, foi necessário acordar que os EUA poderiam excluir o princípio NMF para todos os membros, após um período de seis meses, caso um acordo multilateral não fosse alcançado ${ }^{22}$.

Acordaram também que o tema sobre a liberalização dos serviços deveria ser discutido na Rodada do Uruguai, mas em um acordo diferente denominado GATS (General Agreement on Trade in Services). O GATS então foi o primeiro instrumento de aplicação multilateral e universal no que tange países e setores de serviços respectivamente. No âmbito da $\mathrm{OMC}$, porém, foi um dos acordos mais polêmicos e com resultados menos significativos.

Em resumo, o GATS regula os tipos de medida que a OMC deve aplicar para o comércio de serviços referente à não discriminação (tratamento NMF), transparência, e regulamentação doméstica. Por ser apenas um modelo, são os próprios membros que decidem o setor de serviços que querem liberalizar, em qual extensão e as suas condições ${ }^{23}$. Analisaremos o acordo mais detalhadamente adiante.

\footnotetext{
${ }^{19}$ Organização para a Cooperação e o Desenvolvimento Econômico (OCDE)

${ }^{20}$ Ver item 2.0 para esta definição.

${ }^{21}$ HOWSE, Robert \& TREBILCOCK, Michael Jr. The regulation of Internacional trade. London: Routledge, 2001, p.278.

${ }_{22}^{22}$ Idem, p. 280.

${ }^{23}$ CONDON, Bradly J. NAFTA, WTO and Global Business Strategy: How aids, trade and terrorism affect our economic future. Londres: Quorum Books, 2002, p. 67. 
A Rodada do Uruguai marcou o início das negociações sobre o comércio de serviços, mas ainda é preciso que seja criado um novo sistema de regras para a liberalização dos serviços. Conseqüentemente, foi lançada uma nova rodada para discussão do tema em janeiro de 2000 - a Rodada de Doha. Nesta fase, não se discutiam mais "se" haveria uma liberalização para o comércio de serviços, mas "como" isso poderia ser efetivado.

Em novembro de 2001, a Conferência Ministerial de Doha concordou em abordar uma agenda mais abrangente, a ser concluída em janeiro de 2005. As negociações irão discutir os acordos de agricultura, serviços, assuntos relativos a acesso aos mercados, regras da OMC, comércio e meio ambiente, dentre outros, formando parte do single undertaking ${ }^{24}$, isto é, o acordo é obrigatório na totalidade, não podendo ser tomado por partes.

Atualmente, as negociações estão sendo conduzidas em duas etapas: a fase de regulamentação, quando os membros negociam as novas regras para serviços em subsídios, salvaguardas e aquisições governamentais e a fase de "solicitação e oferta", quando os membros estarão negociando os acessos aos mercados ${ }^{25}$.

Com efeito, hoje, para ser considerado membro da OMC, a apresentação da Lista de Compromissos de obrigações multilaterais, para o setor de serviços, é obrigatória.

\section{CONCEITO DE SERVIÇOS}

Bens e serviços podem ser distinguidos por suas diferentes características. Enquanto aqueles são tangíveis, visíveis, armazenáveis e seu comércio é efetuado pela passagem física pelas fronteiras; estes são considerados intangíveis, invisíveis, não duráveis, transitórios, indivisíveis, esgotáveis e até mesmo porque sua produção e consumo acontecem ao mesmo tempo. No entanto, há muita polêmica com relação a estas definições: como dizer que um desenho de um arquiteto é intangível? Uma peça de teatro invisível? Ou mesmo uma cirurgia plástica não durável? ${ }^{26}$ Devido a estas diferenças conceituais, os membros da OMC e os negociadores da Rodada do Uruguai resolveram adotar uma abordagem distinta para mercadorias e serviços.

\footnotetext{
${ }^{24}$ Disponível em: www.wto.org/english/tratop_e/serv/e/cbt_course_e/c6s1p1_e.htm, acesso em 27/05/04.

${ }^{25}$ CONDON, Bradly J. NAFTA, WTO and Global Business Strategy: How aids, trade and terrorism affect our economic future. Londres: Quorum Books, 2002, p. 68.

${ }^{26}$ HOWSE, Robert \& TREBILCOCK, Michael Jr. The regulation of Internacional trade. London: Routledge, p. 272.
} 
A fim de se estabelecer uma classificação que pudesse facilitar a comparação de dados entre diferentes setores, os serviços foram classificados de duas formas:

\subsection{QUANTO AOS TIPOS:}

Quanto aos tipos, eles podem ser novamente classificados como se segue:

A) Pela natureza do prestador do serviço:

Podem ser serviços comerciais privados, que são os serviços financeiros, de telecomunicações e outros; ou serviços comerciais públicos são os serviços públicos que englobam as atividades de interesse geral assumidas de uma forma ou de outra pela sociedade. A educação, a prevenção sanitária e também o transporte ferroviário e o abastecimento de energia são geralmente serviços públicos.

B) Pela utilização do serviço:

Podem ser os serviços de uso intermediário, que são aqueles que incluem comunicação, transporte, financeiros, eletricidade e gás, distribuição, serviços administrativos e construção; ou serviços de uso final, que consistem nos serviços de recreação, educação, saúde, viagem e turismo e até ambientais.

C) Pela natureza do serviço:

São os serviços de distribuição, isto é, aqueles que se referem a transporte, armazenamento, comunicações ou serviços de produção, que são os serviços financeiros, comerciais e profissionais.

D) Pelo destinatário do serviço:

Podem ser considerados serviços sociais, pois são aqueles voltados para a saúde, educação e serviços sanitários; ou serviços pessoais, que são os que visam o lazer, a cultura e o turismo. 


\subsection{QUANTO À PRESTAÇÃO:}

Os serviços classificados quanto à prestação, são os chamados Modos 1 a 4, usados pela terminologia do GATS. São eles:

Modo 1 - Prestações transfronteiriças (Cross border supply)

São os serviços prestados por uma empresa em um país a um consumidor em outro país. Consiste no movimento do produto do serviço através da fronteira. São os serviços transmitidos por rede de telecomunicações, transporte.Um exemplo seria um investidor no Canadá usando o serviço de um corretor nos EUA pelo telefone ou internet.

\section{Modo 2 - Consumo no Exterior (Consumption Abroad)}

São aqueles prestados com o movimento do consumidor através da fronteira, tais como: turismo, educação, serviços médicos, isto é, são os serviços de consumidos no exterior.

\section{Modo 3 - Presença Comercial (Commercial presence)}

São aqueles cuja presença comercial do prestador do serviço é necessária. Há investimento direto para a prestação do serviço. Alguns exemplos são os escritórios de bancos, agências de publicidade, e outros.

Modo 4 - Presença de Pessoas Físicas (Presence of natural persons)

Neste caso, há movimento temporário da pessoa física que presta o serviço, como consultores, jogadores, músicos. Tem relação direta com as regras de imigração de cada país, já que o país importador deve emitir vistos que permitam a entrada do profissional, para atender o cliente. 
A classificação pela forma de prestação está descrita no GATS e se refere aos tipos de barreiras regulatórias que cada tipo de serviço encontra impedindo maior participação internacional nos mercados. Determina também o tipo de estratégia para entrada em um mercado pelas empresas prestadoras de serviços ${ }^{27}$. No item seguinte examinaremos os tipos de barreiras encontradas para cada tipo de serviço, classificado quanto seu modo de prestação, e os desafios para a liberalização e suas conseqüências.

\section{PROTEÇÃO DAS INDÚSTRIAS DOMÉSTICAS PELOS GOVERNOS - AS} BARREIRAS E A LIBERALIZAÇÃO DO COMÉRCIO DE SERVIÇOS

As barreiras impostas ao comércio são tipicamente regulatórias por natureza ${ }^{28}$. Elas incluem medidas que restringem o acesso aos mercados por firmas estrangeiras, pelo não reconhecimento de qualificações profissionais ou protegendo as indústrias nacionais com monopólios públicos e até mesmo através de tratamento nacional diferenciado, com política fiscal distinta e limitações de empréstimos para firmas estrangeiras ${ }^{29}$, além de restrições quantitativas (QRs). A importância de se identificar estas barreiras, na perspectiva do direito comercial e política, é poder efetivamente facilitar o comércio de serviços com a redução ou até mesmo a remoção das mesmas, gerando com a liberalização, lucros mais significativos que com o comércio de mercadorias ${ }^{30}$.

O modo de prestação de serviços dominante é o da presença comercial (Modo 3) que abrange os serviços financeiros e de telecomunicações. Nestes casos, as barreiras impostas estão relacionadas ao fluxo de FDI (foreign direct investment) ${ }^{31}$. Os países em desenvolvimento têm

\footnotetext{
${ }^{27}$ CONDON, Bradly J. NAFTA,WTO and Global Business Strategy: How aids, trade and terrorism affect our economic future. Londres: Quorum Books, 2002, p. 64-65.

${ }^{28}$ Para HODGE \& MATOO (2002: 247) existem três tipos de barreiras: a) restrições quantitativas tais como cotas, localização e proibições, chamadas de QRs - que se referem às limitações estabelecidas em relação aos valores de importação de determinado produto em um período de tempo ou às restrições à parcela de mercado que prestadores de serviços internacionais podem ter. São complementadas também por medidas não discriminatórias estabelecidas tanto para prestadores de serviços nacionais quanto para estrangeiros. b) Instrumentos de preços, que tomam formas de taxas de vistos de entrada ou tarifas de saída, taxas discriminatórias de aterrisagem para aeronaves e taxas portuárias; c) Padrões, licenças, aquisições e d) acesso discriminatório para redes de distribuição.

${ }^{29}$ HODGE, James. Liberalization of Trade in services in developing countries. In: HOEKMAN, B; MATTOO, A.; ENGLISH, Philip (ed.). Development, trade and the WTO. Washington: BIRD, 2002, p. 222.

${ }^{30}$ HOWSE, Robert \& TREBILCOCK, Michael Jr. The regulation of Internacional trade. London: Routledge, p. 272.

${ }^{31}$ Uma característica dos serviços é que geralmente seu consumo e produção ocorrem simultaneamente. Desta forma, devido a necessidade da proximidade entre fornecedor, fatores de produção e consumidor é preciso que seja feito um investimento direto estrangeiro (FDI); seja na forma de se estabelecer uma presença comercial em território estrangeiro ou pelo movimento temporário do prestador do serviço para atender consumidores estrangeiros. Muitos países acabam por estabelecer barreiras aos investimentos estrangeiros para proteger seus mercados. Estas barreiras são definidas como quaisquer medidas da política governamental que influenciem decisões sobre "onde e como" investir. 
historicamente colocado restrições significativas nestes investimentos, numa tentativa de encorajar o investimento do capital nacional nas suas próprias empresas, limitar a repatriação de lucros, aumentar a ligação das empresas multinacionais com seus fornecedores ${ }^{32}$, além de garantir a independência tanto de suas economias quanto de suas políticas econômicas. Interessante colocar que os Estados Unidos não praticam a liberdade do exercício da atividade bancária no seu território nacional, já que em muitos estados não é possível que estrangeiros pertençam aos conselhos de administração de bancos. Também é necessária autorização de cada um dos estados americanos para que um banco estrangeiro possa operar nos EUA ${ }^{33}$. No entanto, se para economias como China, Hong Kong e Indonésia, os ganhos com a liberalização dos serviços são bem maiores que a liberalização de mercadorias, para países, como Nova Zelândia, Japão, Coréia, Cingapura, Taiwan, União Européia e até os Estados Unidos, o que ocorre é o contrario. Usando índices de medição do fluxo FDI, a China capturaria mais de dois terços do ganho global, oriundos da liberalização do comércio de serviços $^{34}$, enquanto que Estados Unidos e União Européia perderiam.

O segundo modo de prestação mais relevante é o da prestação transfronteiriça (Modo 1). A internet tornou muito difícil a colocação de barreiras pelos estados membros, já que estes tipos de transação não são facilmente detectáveis, principalmente se consistem em serviços de consultoria profissional ${ }^{35}$.

O comércio relacionado aos serviços prestados no exterior (Modo 4) ainda é restrito, mas envolve uma área política extremamente sensível, uma vez que a emissão de vistos para negócios é necessária. A liberalização dos mercados nesta área é problemática para certos países, pois significa obter um controle maior sobre sua própria política de imigração ${ }^{36}$. Alguns países como Japão, Suíça e Canadá, baseando-se na política de concessão de vistos pelos EUA, implantaram medidas restritivas e burocráticas para movimentação de pessoas em seus territórios, numa clara limitação de seus mercados ${ }^{37}$.

Finalmente, no caso dos tipos de serviços de consumo no exterior (Modo 2), as barreiras relevantes são relacionadas aos vistos concedidos ao consumidor e não deveriam implicar em grandes problemas. No entanto, devido às políticas restritivas de concessão de vistos impostas por

\footnotetext{
${ }^{32}$ HODGE, James. Liberalization of Trade in services in developing countries. In: HOEKMAN, B; MATTOO, A.; ENGLISH, Philip (ed.). Development, trade and the WTO. Washington: BIRD, 2002, p. 222.

${ }^{33}$ RAINELLI, Michel. A Organização Mundial de Comércio, Lisboa: Terramar, 1998, p. 116.

${ }^{34}$ HOECKMAN, Bernard M.; KOSTECKI, Michael M., The political economy of the world trading system. The WTO and beyond. Nova York: Oxford University Press, 2001, p.244.

${ }^{35}$ CONDON, Bradly J. NAFTA,WTO and Global Business Strategy: How aids, trade and terrorism affects our economic future. Londres: Quorum Books, 2002, p. 64.

${ }^{36}$ Ibidem

${ }^{37}$ GOYOS JUNIOR, Durval de Noronha. A OMC e os Tratados da Rodada do Uruguai. São Paulo: Observador Legal, 1994, p.55. 
alguns países a fim de limitar os seus mercados para prestação de serviços por pessoas físicas estrangeiras, como dito acima, alguns setores nacionais como turismo e educação acabaram tendo barreiras estabelecidas em seus próprios mercados.

A liberalização do comércio de serviços consiste na redução de barreiras regulatórias a fim de permitir acesso aos mercados, assim como na diminuição do tratamento nacional discriminatório para todos os tipos de serviços. Entretanto, não deve ser confundida com o processo de desregulamentação da economia pelo qual muitos países estão passando. $O$ foco da desregulamentação é reduzir a participação estatal em determinados setores, enquanto que o da liberalização é assegurar que a legislação existente não discrimine fornecedores estrangeiros naquele mercado. A liberalização coexiste com a preocupação contínua dos governos em suas políticas de proteção do consumidor, controle dos monopólios naturais, administração da economia, proteção e fomento do desenvolvimento nacional e principalmente a consecução de seus objetivos sociais $^{38}$. Estabelecer esta diferença ajudará os legisladores a enfrentar o grande desafio de por um lado, fomentar a saudável competição entre fornecedores incluindo os estrangeiros enquanto que de outro, assegurar a necessidade de regras para os prestadores dos serviços de determinados setores, visando sempre seus interesses nacionais.

\section{O ACORDO}

\subsection{OBJETIVO}

Conforme estabelecido no preâmbulo do GATS, o objetivo do acordo é o de contribuir para expansão do comércio "sob condições de transparência e liberalização progressiva, como instrumento de promoção do crescimento da economia de todos os estados membros e o desenvolvimento dos países em desenvolvimento". ${ }^{39}$ De acordo com as informações disponibilizadas no próprio site da $\mathrm{OMC}^{40}$, a contribuição do GATS para o comércio mundial de serviços, se baseia em dois pilares principais: a) assegurar a crescente transparência e previsibilidade de regras relevantes e b) promover a liberalização progressiva através de sucessivas rodadas de negociações. Estas visam promover os interesses dos participantes em bases

\footnotetext{
${ }^{38}$ Ver: HODGE, James. Liberalization of Trade in services in developing countries. In: HOEKMAN, B; MATTOO, A.; ENGLISH, Philip (ed.). Development, trade and the WTO. Washington: BIRD, 2002, p. 222. \& HOECKMAN, Bernard M.; KOSTECKI, Michael M., The political economy of the world trading system. The WTO and beyond. Nova York: Oxford University Press, 2001, p.247.

${ }^{39}$ GATS

${ }^{40}$ Disponível em: www.wto.org/english/tratop e/serv e/cbt course e/c1s2p1 e.htm. Acesso em: 27/05/04 
mutuamente vantajosas assegurando o equilíbrio entre direitos e obrigações assim como observando os objetivos da política nacional ${ }^{41}$.

O GATS foi inspirado de acordo com o pré-existente GATT e acabou por utilizar termos e conceitos já conhecidos no comércio de mercadorias. Com efeito, os princípios NMF (tratamento da nação mais favorecida) e tratamento nacional foram amplamente vinculados aos setores de serviços abordados pelo GATS.

Desta forma, os dois acordos apresentam algumas semelhanças, descritas no site da $\mathrm{OMC}^{42}$ e que serão abordadas ao longo deste trabalho. A primeira delas se encontra no princípio NMF, que se refere à obrigação de dar a todas as nações membros o mesmo tratamento para os setores de serviços abrangidos pelo GATS. Outra semelhança se encontra na tabela tarifária do GATT, pela qual os países membros vinculam suas concessões tarifárias para importação de mercadorias e que tem sua equivalência na lista de compromissos específicos que definem as condições relevantes para os serviços.

No entanto, há diferenças substanciais no que tangem o conteúdo e objeto dos dois acordos, e que justificam, portanto a necessidade de se ter negociado um acordo distinto para o comércio de serviços.

A primeira delas se refere ao objeto dos acordos. Enquanto o GATT visa regular as tarifas alfandegárias que afetam o produto, o GATS apresenta medidas que afetam tanto o produto (serviço) quanto o fornecedor, uma vez que não é possível apontar o serviço quando ele cruza a fronteira e desta forma, as políticas restritivas são estabelecidas a fim de se limitar o acesso de prestadores de serviços e fornecedores estrangeiros nos mercados domésticos;

Outra diferença se encontra na própria definição do comércio de serviços, que cobre não apenas a prestação transfronteiriça, mas os outros três tipos de transações: a presença comercial, o consumo no exterior e a presença de pessoas físicas para prestação de serviços.

Por fim, o GATT oferece acesso aos mercados, livre de cotas e princípio do tratamento nacional, enquanto que o GATS faz esta abordagem setorialmente e apenas no limite de cada Lista

\footnotetext{
${ }^{41}$ THORSTENSEN, Vera. OMC - Organização Mundial do Comércio. As regras do comércio internacional e a nova rodada de negociações multilaterais São Paulo: Aduaneiras, 2001, p.197.

${ }^{42}$ Disponível em: www.wto.org/english/tratop e/serv e/cbt course e/c1s2p1 e.htm. Acesso em: 27/05/04 
de Compromissos oferecida pelos países membros.

\section{2 . ESTRUTURA}

O GATS foi negociado em quatro partes distintas ${ }^{43}$ e é visto por muitos autores como complexo, sendo a lista de compromissos específicos, a real substância do acordo.

A primeira parte ${ }^{44}$, apresenta o quadro geral de obrigações, que contem 29 artigos divididos em seis partes: âmbito e definição, obrigações e disciplinas gerais, compromissos específicos, liberalização progressiva, disposições institucionais e disposições finais.

Os anexos setoriais, que são as disposições de caráter específico para determinados setores como movimento de pessoas físicas, transporte aéreo, serviços financeiros e telecomunicações, consistem na segunda parte.

A terceira parte engloba a Lista de Compromissos de Liberalização, que é a série de compromissos de liberalização ou o acesso a mercado e tratamento nacional, para cada setor, assumidos pelos Estados membros.

Finalmente, a última parte consiste na Lista de Exceções à cláusula da nação mais favorecida, onde os países membros indicaram quais setores permaneceriam fora do âmbito do princípio NMF. Importante mencionar que esta lista não foi mais permitida no GATS, por este motivo, alguns autores não consideram este item. ${ }^{45}$

\subsubsection{O alcance do acordo}

O GATS abrange todos os tipos de serviços ${ }^{46}$, com exceção àqueles serviços prestados "no exercício das autoridades governamentais", a menos que concorram com empresas privadas, isto é,

\footnotetext{
${ }^{43}$ De acordo com THORSTENSEN, Vera. OMC - Organização Mundial do Comércio. As regras do comércio internacional e a nova rodada de negociações multilaterais São Paulo: Aduaneiras, 2001, p. 196.

${ }^{44}$ Partes I a VI do GATS

${ }^{45}$ Ver: MARCONINI, Marco. OMC, acordos regionais e o comércio de serviços:normativa internacional e interesse brasileiro.São Paulo: Aduaneiras, 2003, p.72. \& GOYOS JUNIOR, Durval de Noronha. A OMC e os Tratados da Rodada do Uruguai. São Paulo: Observador Legal, 1994, p.54.

${ }^{46}$ A prestação do serviço inclui sua produção, distribuição, publicidade, suas vendas e sua entrega.

Revista do Programa de Mestrado em Direito do UniCEUB, Brasília, v. 2, n. 2, p.502-526, jul./dez. 2005 
os não monopólios ${ }^{47}$. Exemplos típicos incluem polícia, proteção contra incêndios, administração de alfândegas, e outros.

Sendo assim, de acordo com o GATS, não tem relevância, o nível de qualquer decisão tomada em âmbito nacional, seja ela federal, estadual, municipal ou mesmo por corpos não governamentais que exerçam poderes delegados ${ }^{48}$. Estas decisões devem estar todas de conformidade com o acordo, sejam elas leis, regras, procedimentos, etc, referentes ao comércio de serviços no que diz respeito à compra e pagamento pelo uso de um serviço; a presença, incluindo a presença comercial de pessoas de um Estado membro para prestação de um serviço no território de outro membro; assim como o acesso e o uso de serviços que são solicitados por Estados membros a serem oferecidos para o público em geral.

\subsubsection{Princípios e obrigações gerais}

Os princípios, tratados na Parte II do GATS, têm como finalidade evitar critérios discriminatórios. São eles:

O Princípio do Tratamento da Nação Mais Favorecida (NMF) ${ }^{49}$ estabelece que todas as vantagens, favorecimentos, privilégios e imunidades, concedidas por um Estado membro da OMC a algum outro Estado membro, deverão ser estendidos também a todos os outros Estados membros. No caso do GATS, estendem-se apenas no que concernem os compromissos da Lista de cada país, podendo, ainda assim estabelecer exceções que deixariam de existir após um prazo de 10 anos. Uma vez membro, qualquer exceção adicional deve ser solicitada e aprovada por três quartos dos membros da Conferência Ministerial da OMC.

A necessidade de um anexo a este princípio surgiu com a preocupação principalmente dos Estados Unidos, que consideraram que os compromissos de certos países não correspondem a uma verdadeira abertura dos mercados. Com efeito, a aplicação da cláusula NMF beneficiaria estes países sem oferecer contrapartidas especialmente nos setores de serviços financeiros e telecomunicações. Mais de 60 membros submeteram exceções NMF em 1994, envolvendo

\footnotetext{
${ }^{47}$ GATS Arts I:3b,I:3c.

${ }^{48}$ GATS Art. I:3a.

${ }^{49}$ GATS, Art II. 
particularmente três importante setores: a) serviços audiovisuais, objetivando proteger acordos preferenciais de co-produção ou distribuição com certos países; b) financeiros, buscando mais reciprocidade em acesso aos mercados, e c) transportes (marítimo, terrestre e aéreo). Os países em desenvolvimento foram motivados pelo código da UNCTAD em reservar até $40 \%$ de suas rotas de envio para embarcações com bandeiras nacionais.

O Princípio da transparência ${ }^{50}$ determina que os membros devem publicar todas as medidas relevantes de aplicação geral que se relacionam com o acordo e Acordos Internacionais que afetem o comércio de serviços pelo menos uma vez ao ano.

As obrigações descritas no GATS se referem à participação crescente dos países em desenvolvimento, integração econômica, regulamentação doméstica, reconhecimento de diplomas, monopólios, medidas de salvaguarda, pagamentos e subsídios. Estes temas serão descritos abaixo.

A primeira delas se refere à participação crescente dos países em desenvolvimento, que deverá ser facilitada através da negociação de compromissos específicos relativos “(a) ao fortalecimento da capacitação, eficiência e competitividade, mediante acesso à tecnologia em uma base comercial; (b) melhoria do acesso aos canais de distribuição e redes de informação; (c) liberalização de acesso a mercado e modalidades de prestação de serviços exportáveis". ${ }^{51}$

A regulamentação doméstica. $^{52}$ estipula que as medidas judiciais, arbitrais ou administrativas que afetam o comércio de serviços devem ser tomadas, pelos tribunais locais, de maneira razoável, objetiva e imparcial a fim de se evitar a criação de barreiras desnecessárias.

A possibilidade do reconhecimento de documentos e diplomas ${ }^{53}$ visa buscar estes reconhecimentos através da harmonização baseados em acordos anteriores. Um membro poderá oferecer acesso a esses acordos a outros membros interessados. Esta obrigação tem como objetivo facilitar a eliminação das barreiras que poderiam ser impostas para a prestação de serviços pela presença de pessoas físicas estrangeiras no mercado nacional (Modo 4).

No caso dos monopólios e prestadores exclusivos, o prestador de serviço que tenha monopólio em seu próprio país deve obedecer a Lista de compromissos de seu país, ou seja, deve

\footnotetext{
${ }^{50}$ GATS Art.III.

${ }^{51}$ GATS, Art IV:a,b, c.

${ }^{52}$ GATS, Art VI.

${ }^{53}$ GATS, Art VII. 
atuar de forma consistente com as obrigações e compromissos da NMF. ${ }^{54}$

Quanto à integração econômica ${ }^{55}$, o acordo não poderá obstar os membros de se unirem em blocos. Já os subsídios são previstos no art. XV e requerem cuidados especiais para não distorcer o comércio de serviços, impondo condições que tenham efeitos negativos, enquanto que o art. XI refere-se aos pagamentos e transferências e determina que um membro não deve aplicar restrições de pagamentos aos compromissos específicos.

$\mathrm{O}$ art $\mathrm{X}$ que dispõe sobre as medidas de salvaguarda e emergências, estipula que em 3 anos deverá haver negociações multilaterais sobre estas medidas, baseadas no princípio da não discriminação. No entanto, qualquer modificação ou retirada de algum compromisso específico da Lista de Compromissos por um país membro, não pode ser usada pelos demais países-membros como pré ao conceito de texto para limitar a abrangência da liberalização baseada no princípio $\mathrm{NMF}^{56}$. Compensações deverão ser oferecidas e caso necessário, pode-se buscar a arbitragem para resolver disputas. Outra diferença em comparação ao GATT cujo conceito de renúncia é apenas temporária em relação aos compromissos no caso das medidas de salvaguarda e emergências. Importante notar que os compromissos dos países-membros consistem em regulamentações domésticas específicas e dependendo de vários fatores, dentre eles, avanços tecnológicos e até mesmo condições econômicas e sociais, estas regulamentações necessitarão de ajustes ao longo do tempo. $^{57}$

\subsubsection{Compromissos específicos}

Por ser um acordo extremamente flexível, o GATS permite que cada membro ajuste as condições para abertura de seu mercado de serviços. Neste sentido, dois tipos de obrigações são relevantes, mais propriamente chamadas de compromissos específicos: o princípio do tratamento nacional e o do acesso aos mercados. De acordo com a Parte III do GATS, os membros podem designar setores de serviços e listá-los em sua lista de compromissos, assumindo obrigações e limitações, a fim de ter o direito de aplicar medidas inconsistentes com o acesso aos mercados e tratamento nacional. Estas medidas são válidas apenas para aqueles setores constantes das listas de

\footnotetext{
${ }^{54} \mathrm{O}$ art XXVIII(h) especifica o que seria um fornecedor que tenha um monopólio: É a entidade que foi estabelecida formalmente ou na prática, e o único a oferecer aquele serviço.

${ }^{55}$ GATS, Art V

${ }^{56}$ GATS, Art XXI, 2(a).

${ }^{57}$ HOWSE, Robert \& TREBILCOCK, Michael Jr. The regulation of Internacional trade. London: Routledge, p. 290 
compromissos de cada país membro.

O princípio do Tratamento nacional, previsto no art XVII do GATS, consiste em oferecer tratamento igual tanto para os prestadores de serviços nacionais como para os estrangeiros. Este tratamento pode ou não ser idêntico ao aplicado às empresas domésticas, já que o dispositivo poderia piorar as condições de competitividade para as empresas estrangeiras sem sede no país. (Um exemplo seria o requisito de empresas de seguro possuírem reservas locais) ${ }^{58}$. Interessante perceber, a primeira vista, que o princípio do tratamento nacional no GATS é muitas vezes considerado mais limitado na prática, que no GATT. Isto se dá, porque no comércio de mercadorias, acatar o princípio do tratamento nacional em sua universalidade, nem sempre significa em comércio livre. Nestes casos, as importações podem ser controladas por imposições de tarifas determinadas pelos acordos tarifários de cada país. Por outro lado, no caso do comércio de serviços, estas medidas tarifárias não funcionam e a aplicação do princípio do tratamento nacional seria o equivalente a garantir acesso livre aos mercados ${ }^{59}$.

$\mathrm{O}$ acesso aos mercados ${ }^{60}$ estipula medidas variadas que um membro não pode aplicar para restringir o mercado, a menos que estejam listadas. As medidas incluem restrições quanto: a) Número de fornecedores permitidos, b) Valor das transações ou do ativo, c) Quantidade total dos serviços prestados, d) Número de pessoas a serem empregadas, e) Tipo de empresa através da qual irá prestar o serviço (ex: banco - filial ou subsidiária?), f) Participação de capital estrangeiro quanto aos limites relativos ao acionista estrangeiro ou ao valor absoluto do investimento estrangeiro.

Estas medidas, com exceção dos itens "e" e "f”, não são necessariamente discriminatórias por afetarem tanto os prestadores locais quanto os estrangeiros. No entanto, acreditava-se que eram medidas de particular importância.

\subsubsection{Liberalização progressiva ${ }^{61}$.}

Como dito anteriormente, cada membro define os setores de serviços e os critérios

\footnotetext{
${ }^{58}$ HOECKMAN, Bernard M.; KOSTECKI, Michael M., The political economy of the world trading system. The WTO and beyond. Nova York: Oxford University Press, 2001, p.253.

${ }^{59}$ Disponível em: www.wto.org/english/tratop_e/serv_e/cbt_course e/c2s5p1_e.htm. Acesso em 27/05/04.

${ }^{60}$ GATS, Parte III, art XVI

${ }^{61}$ GATS, Partes IV, V \& VI

Revista do Programa de Mestrado em Direito do UniCEUB, Brasilia, v. 2, n. 2, p.502-526, jul./dez. 2005 
detalhados dos compromissos e obrigações para estabelecer os parâmetros da liberalização dentro de seu território. Estes termos e condições devem ser expressos por meio da Lista de Compromissos. A Lista de Compromissos só pode ser alterada com o acordo comum das partes envolvidas e no prazo de três anos. Qualquer membro afetado pela mudança pode solicitar algum tipo de compensação. A Lista de Compromissos tem validade de 10 anos e está sujeita à revisão após cinco anos de entrar em vigor.

A lista de Compromissos deverá conter:

a) Termos, limites e condições de acesso ao mercado,

b) Condições e qualificações ao tratamento nacional (qual a dimensão do favoritismo aos fornecedores locais)

c) Comprometimentos adicionais

d) Data para compromissos começarem a valer.

A tabela abaixo ilustra o formato das Listas de Compromissos. 


\begin{tabular}{|c|c|c|c|}
\hline $\begin{array}{l}\text { Setor ou sub- } \\
\text { setor }\end{array}$ & $\begin{array}{c}\text { Limitações ao acesso aos } \\
\text { mercados }\end{array}$ & $\begin{array}{c}\text { Limitações ao } \\
\text { tratamento nacional }\end{array}$ & $\begin{array}{c}\text { Compromissos } \\
\text { adicionais }\end{array}$ \\
\hline \multicolumn{4}{|c|}{ I. COMPROMISSOS HORIZONTAIS } \\
\hline $\begin{array}{l}\text { Todos } \quad \text { os } \\
\text { setores } \\
\text { incluídos nesta } \\
\text { lista }\end{array}$ & $\begin{array}{l}\text { 4) Nenhum compromisso } \\
\text { feito, exceto para a) } \\
\text { presenças temporárias no } \\
\text { caso de transferidos dentro } \\
\text { de uma empresa, ou } \\
\text { executivos seniors e } \\
\text { especialistas e b) presença } \\
\text { de até } 90 \text { dias para } \\
\text { representantes de prestador } \\
\text { de serviços para negociar } \\
\text { vendas de serviços. }\end{array}$ & $\begin{array}{l}\text { 1) Nenhuma exceção } \\
\text { mantida } \\
\text { 2) Nenhum } \\
\text { compromisso feito } \\
\text { 3) Autorização para } \\
\text { aquisição de terras } \\
\text { por estrangeiros. } \\
\text { 4) Nenhuma exceção } \\
\text { mantida }\end{array}$ & \\
\hline \multicolumn{4}{|c|}{ II. COMPROMISSOS VERTICAIS } \\
\hline $\begin{array}{l}\text { 4. Serviços } \\
\text { distribuição }\end{array}$ & 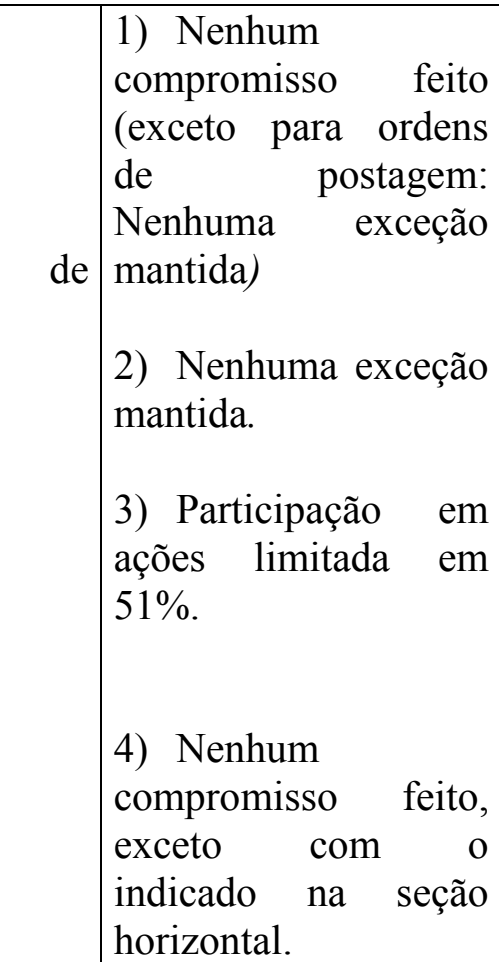 & $\begin{array}{l}\text { 1) Nenhum } \\
\text { compromisso feito } \\
\text { (exceto para ordens } \\
\text { de postagem: } \\
\text { Nenhuma exceção } \\
\text { mantida) } \\
\text { 2) Nenhuma exceção } \\
\text { mantida } \\
\text { 3) Ajudas de } \\
\text { investimento somente } \\
\text { para empresas de } \\
\text { controle nacional. } \\
\text { 4) Nenhum } \\
\text { compromisso feito }\end{array}$ & $\begin{array}{l}\text { Estabelecimento de } \\
\text { um regulamentador } \\
\text { independente. }\end{array}$ \\
\hline
\end{tabular}

\footnotetext{
${ }^{62}$ As limitações ao acesso ao mercado podem ser qualquer uma das seis descritas no item 4.2.3 deste trabalho.

${ }^{63} \mathrm{O}$ termo utilizado no acordo "none" significa que nenhuma exceção é mantida, ou seja, não se aplicarão medidas inconsistentes com os princípios de acesso aos mercados e tratamento nacional para aquele compromisso.

${ }^{64} \mathrm{O}$ termo "unbound" utilizado nas listas de compromissos, significa que nenhum compromisso foi feito para aquele setor, ou seja, o país pode aplicar qualquer medida restritiva para aquele item.
} 


\section{SETORES MAIS ATINGIDOS}

Neste item discutiremos as questões que mais mereceram destaque após a Rodada do Uruguai. O GATS estabeleceu conselhos para continuar discutindo as questões pendentes principalmente sobre os setores de serviços financeiros, de telecomunicações e transporte marítimo. As negociações destes dois últimos deverão permanecer em contínuo desenvolvimento como veremos adiante.

\subsection{Finanças}

O Anexo sobre serviços financeiros surgiu devido à grande importância dada pelos EUA ao assunto, refletindo a força do lobby deste setor que visa um aumento do acesso aos mercados. Geralmente, todos os governos do mundo regulam de perto os bancos, companhias de seguro e outros prestadores de serviços. Um dos elementos centrais deste anexo é o chamado "prudential carve-out", ou seja, confirma na essência que qualquer membro do GATS é livre para tomar medidas prudenciais a fim de proteger investidores, depositários, segurados, credores fiduciários de uma instituição financeira ou mesmo para garantir a integridade e estabilidade do sistema financeiro $^{65}$. Estas medidas não são consideradas transgressoras da cláusula NMF. Embora um número maior de países em desenvolvimento reconheça que um setor de serviços financeiros mais competitivo e eficiente está diretamente relacionado a desenvolvimento econômico e que a abertura do mercado para instituições financeiras estrangeiras possa fortalecer os sistemas financeiros domésticos, ainda há a preocupação de que a liberalização deste serviço enfraqueça as instituições locais ${ }^{66}$ e conseqüentemente fragilize a economia nacional.

Apesar ter sido um dos temas mais difíceis da Rodada do Uruguai, pois se aventou até a possibilidade de negociar um acordo sobre serviços financeiros em separado, foi a área que mais avançou no GATS. Em 1998, 68 países enviaram compromissos e 29 melhoraram as condições de acesso aos mercados.

O Brasil, durante a Rodada do Uruguai, sofreu fortes pressões em acordos bilaterais, para liberalizar seu setor de serviços financeiros, já que este setor representava aproximadamente $20 \%$ do PIB brasileiro, oferecia uma lucratividade sem retorno em relação à qualidade aos serviços

\footnotetext{
${ }^{65}$ GATS - Anexo sobre serviços financeiros, parágrafo 2.a).

${ }^{66}$ HOECKMAN, Bernard M.; KOSTECKI, Michael M., The political economy of the world trading system. The WTO and beyond. Nova York: Oxford University Press, 2001, p.259. 
oferecidos e ainda apresentava riscos muito altos, incompatíveis, mas inerentes à operação bancária $^{67}$. A Constituição Federal de 1988, em seu art. 52 das disposições transitórias, proíbe a instalação de novas instituições financeiras de origem estrangeira ou o aumento de participação no capital daquelas já existentes, até que haja regulamentação do assunto em lei complementar, disposta pelo artigo 192. O art. 192 da CF 1988 foi alterado pela Emenda Constitucional n. 40 de 29 de maio de 2003, mas ainda aguarda Lei complementar para dispor sobre a participação do capital estrangeiro nas instituições financeiras que o integram.

Na Rodada de Doha, alguns países já apresentaram propostas para o desenvolvimento do acordo. Os EUA defendem princípios de liberalização fundamentais que incluem: descrição clara e uniforme dos setores abrangidos pelos compromissos de liberalização; remoção das restrições sobre formas de presença comercial (subsidiária, escritório ou joint venture); remoção de restrições na prestação de serviços financeiros de forma integrada (cross border basis); remoção de limitações quantitativas sobre o número dos prestadores na forma de quotas, monopólios ou prestadores exclusivos; liberalização da entrada de profissionais, com a remoção de discriminação em termos de leis, regulamentos e práticas ${ }^{68}$.

\subsection{Telecomunicações}

O setor de comunicação tem um papel duplo - o de ser um setor econômico independente, por um lado e por outro, de servir como meio de fornecimento de outras atividades econômicas, como o comércio eletrônico ou mesmo transferência de moeda. Desta forma, o anexo sobre telecomunicações acabou por refletir estes elementos característicos.

Os compromissos de acesso aos mercados foram feitos sobre telefonia à voz, serviços por telefone local e à longa distância, serviços internacionais, transmissão de dados, telefone celular, circuitos privados e serviços por satélite, disciplinas regulatórias sobre concorrência, interconexão e licenciamento.

Inicialmente, como no anexo sobre serviços financeiros, os EUA tinham a impressão de que

\footnotetext{
${ }^{67}$ GOYOS JUNIOR, Durval de Noronha. A OMC e os Tratados da Rodada do Uruguai. São Paulo: Observador Legal, 1994, p.64.

${ }^{68}$ TH ORSTENSEN, Vera. OMC - Organização Mundial do Comércio. As regras do comércio internacional e a nova rodada de negociações multilaterais São Paulo: Aduaneiras, 2001, p.464. 
as propostas oferecidas eram inadequadas e retiraram a oferta de abertura ao acesso ao mercado de satélite e as negociações entraram em colapso. Alguns negociadores acharam que os EUA estavam atendendo aos interesses de um grupo local muito restrito. Diferentemente ao acordo sobre serviços financeiros, foi o próprio Diretor Geral da OMC que teve a iniciativa de retomar as negociações, induzindo os maiores interessados a estender o prazo para a conclusão das negociações até Fevereiro de $1997^{69}$. Finalmente, 80 compromissos foram feitos ${ }^{70}$ e todo o processo de privatizações e reformas que decorreram do acordo.

Há duas razões para que as reformas continuem sendo feitas. A primeira, como já dito anteriormente, é que existe uma percepção disseminada de que o setor de telecomunicações se tornou instrumento vital para a infraestrutura econômica de suporte para crescimento e desenvolvimento, a segunda é a urgência para a modernização deste setor, provocado pela economia digital e comércio eletrônico ${ }^{71}$.

Interessante que neste setor, tanto os países desenvolvidos quanto os em desenvolvimento demonstram interesse nas reformas e no avanço das negociações do GATS. Os primeiros por verem a oportunidade em ampliar seus mercados internacionais e os últimos por terem as reformas como prioritárias para seu desenvolvimento econômico. Outro fator de surpresa para alguns países que abriram seu setor é que suas empresas locais se transformaram em competidores internacionais, muitas vezes individualmente ou através de consórcios e puderam ver seus próprios compromissos em telecomunicações como meios de atrair investimentos estrangeiros, além de terem desenvolvido interesses no mercado internacional. O maior desafio agora é elaborar seus compromissos que reflitam os anseios nacionais.

\subsection{Transporte marítimo}

O anexo estabelece o uso da cláusula NMF para transportes marítimos para todos os membros que não fizeram compromissos específicos através das Listas de Compromissos. As negociações deste setor foram suspensas em 1996, voltando em Doha. Vários países apresentaram propostas para negociações incluindo EUA, UE e Japão. Este último identifica as barreiras de

\footnotetext{
${ }^{69}$ HOECKMAN, Bernard M.; KOSTECKI, Michael M., The political economy of the world trading system. The WTO and beyond. Nova York: Oxford University Press, 2001, p.279.

${ }^{70}$ HODGE, James. Liberalization of Trade in services in developing countries. In: HOEKMAN, B; MATTOO, A.; ENGLISH, Philip (ed.). Development, trade and the WTO. Washington: BIRD, 2002, p. 272.

${ }^{71}$ Idem, 2002, p. 272.

Revista do Programa de Mestrado em Direito do UniCEUB, Brasília, v. 2, n. 2, p.502-526, jul./dez. 2005 
acordo com suas expectativas e são elas: restrição ao capital estrangeiro, medidas de favorecimento de navios de bandeira nacional e empresas nacionais, restrições aos novos prestadores e restrições legais ao tipo de empresas ${ }^{72}$.

\section{CONCLUSÃO}

Há um reconhecimento generalizado de que o comércio internacional de serviços pode trazer um grande aumento de lucros. No entanto, este comércio ainda necessita de políticas regulatórias antes que certos tipos de liberalização sejam realizadas. O GATS foi o primeiro acordo internacional sobre serviços universal e multilateral. Apesar de avançar de forma muito lenta, acredita-se que mais tópicos deverão ser discutidos, ampliando as discussões em torno do tema. $\mathrm{O}$ acordo determina que o processo de liberalização deverá evoluir em diversas rodadas de negociação. Dentre elas, uma revisão de todas as exceções dispostas nas Listas de Compromissos dos países, após cinco anos, visando os interesses de todos os participantes e baseando-se em vantagens mútuas. As negociações da Rodada de Doha deverão ser finalizadas em 1 Janeiro de 2005, até lá, muitos interesses serão considerados. Enquanto os europeus e americanos pressionam por uma rápida liberalização de serviços, países como o Brasil (integrantes do Grupo de Cairns ${ }^{73}$ ) buscam um avanço paralelo na área agrícola ${ }^{74}$. Apesar de serem acordos independentes, estão intimamente ligados e um não avançará sem o outro.

\section{REFERÊNCIAS}

COBUILD, Collins. English Language Dictionary. 2. ed. Londres: Harper Collins Publishers, 1993.

CONDON, Bradly J. NAFTA,WTO and Global Business Strategy: How aids, trade and terrorism affect our economic future. Londres: Quorum Books, 2002.

GATS. Disponível em www.wto.org. Acesso em 17/02/04.

GOYOS JUNIOR, Durval de Noronha. A OMC e os Tratados da Rodada do Uruguai. São Paulo:

\footnotetext{
${ }^{72}$ THORSTENSEN, Vera. OMC - Organização Mundial do Comércio. As regras do comércio internacional e a nova rodada de negociações multilaterais São Paulo: Aduaneiras, 2001, ps.469/470.

${ }^{73}$ Grupo de Cairns: África do Sul, Argentina, Austrália (que ocupa o papel de coordenação), Bolívia, Brasil, Canadá, Chile, Colômbia, Costa Rica, Filipinas, Guatemala, Indonésia, Malásia, Nova Zelândia, Paraguai, Tailândia, Uruguai.

${ }^{74}$ Correio Brasiliense, 14/06/04, p.7.

Revista do Programa de Mestrado em Direito do UniCEUB, Brasília, v. 2, n. 2, p.502-526, jul./dez. 2005 
Observador Legal, 1994.

HODGE, James. Liberalization of trade in services in developing countries. In: HOECKMAN, B.; MATOO, A.; ENGLISH, Philip (ed.) Development, trade and the WTO. Washington: BIRD, 2002.

HOECKMAN, Bernard M.; KOSTECKI, Michael M., The political economy of the world trading system. The WTO and beyond. Nova York: Oxford University Press, 2001.

HOWSE, Robert \& TREBILCOCK, Michael Jr. The regulation of Internacional trade. London: Routledge, 2001.

MARCONINI, Marco. OMC, acordos regionais e o comércio de serviços:normativa internacional e interesse brasileiro. São Paulo: Aduaneiras, 2003.

RAINELLI, Michel. A Organização Mundial de Comércio, Lisboa: Terramar, 1998.

THORSTENSEN, Vera. OMC - Organização Mundial do Comércio. As regras do comércio internacional e a nova rodada de negociações multilaterais São Paulo: Aduaneiras, 2001.

WTO - SERVIÇOS - MÓDULO DE TREINAMENTO DO GATS - Disponível em: http://www.wto.org/english/tratop_e/serv_e/cbt_course_e/clslpl_e.htm. Acesso em 27/05/04. 